\title{
CORRIGENDUM Epidemiology of varicella zoster virus infection in Canada and the United Kingdom - CORRIGENDUM
}

M. BRISSON, W. J. EDMUNDS, B. LAW, N. J. GAY, R. WALLD,

M. BROWNELL, L.L. ROOS AND G. DE SERRES

doi: 10.1017/S0950268801005921, Published online by Cambridge University Press, 26 November 2001

The above published article by Brisson et al. (2001) contains an error in the spelling of an author's name.

L. ROOS, should read: L.L. ROOS

This error has now been rectified in the online version of this article.

\section{REFERENCE}

1. Brisson M, Edmunds WJ, Law B, Gay NJ, Walld R, Brownell M, Roos LL, De Serres G. Epidemiology of varicella zoster virus infection in Canada and the United Kingdom. Epidemiology and Infection 2001; 127: 305-314, doi: 10.1017/ S0950268801005921. 


\title{
Epidemiology of varicella zoster virus infection in Canada and the United Kingdom:
}

\author{
M. BRISSON ${ }^{1,2,3 *}$, W. J. EDMUNDS ${ }^{1,2}$, B. LAW ${ }^{4,5}$, N. J. GAY ${ }^{1}$, R. WALLD ${ }^{5}$, \\ M. BROWNELL ${ }^{5}$, L. L. ROOS ${ }^{5}$ AND G. DE SERRES 3 \\ ${ }^{1}$ PHLS CDSC, 61 Colindale Avenue, London NW9 5EQ \\ ${ }^{2}$ City University, London ECIV OHB \\ ${ }^{3}$ Public Health Research Unit, CHUL Research Centre, Faculty of Medicine, Laval University, Quebec \\ ${ }^{4}$ Department of Pediatrics and Child Health, University of Manitoba, Winnipeg \\ ${ }^{5}$ Manitoba Centre for Health Policy and Evaluation and Department of Community Health Sciences, \\ University of Manitoba, Winnipeg
}

(Accepted 11 May 2001)

\section{SUMMARY}

Many countries are currently studying the possibility of mass vaccination against varicella. The objective of this study was to provide a comprehensive picture of the pre-vaccine epidemiology of the varicella zoster virus (VZV) to aid in the design of immunization programs and to adequately measure the impact of vaccination. Population-based data including physician visit claims, sentinel surveillance and hospitalization data from Canada and the United Kingdom were analysed. The key epidemiological characteristics of varicella and zoster (age specific consultation rates, seasonality, force of infection, hospitalization rates and inpatient days) were compared. Results show that the overall epidemiology of varicella and zoster is remarkably similar between the two countries. The major difference being that, contrary to Canada, the epidemiology of varicella seems to be changing in the United Kingdom with an important decrease in the average age at infection that coincides with a significant increase in children attending preschool. Furthermore, differences exist in the seasonality between the United Kingdom and Canada, which seem to be primarily due to the school calendar. These results illustrate that school and preschool contact patterns play an important role in the dynamics of varicella. Finally, our results provide baseline estimates of varicella and zoster incidence and morbidity for VZV vaccine effectiveness and cost-effectiveness studies.

\section{INTRODUCTION}

Varicella zoster virus (VZV) produces two distinct clinical syndromes: varicella and zoster. Varicella or chickenpox is the primary manifestation of VZV infection. In temperate climates in the absence of vaccine, the lifetime risk for varicella is over $95 \%$ [1]. Over $90 \%$ or more of cases occur during the first 15 years of life and the burden of illness is predominantly borne by otherwise healthy children [2-4]. Following

* Author for correspondence.

$\$$ The original version of this article was published with an incorrect author name. A notice detailing this has been published and the error rectified in the online PDF and HTML copies. primary infection the virus becomes latent in dorsal root ganglia and may reactivate decades later to cause zoster, also known as shingles, in a significant proportion of the population $[5,6]$. The events leading to reactivation are not clearly understood although decreased cell-mediated immunity is thought to play a major role [6]. The overwhelming burden of illness due to zoster is suffered by the elderly due not only to the increased incidence of reactivation after age 50 but also the increased frequency of post-herpetic neuralgia $[6,7]$. 
A live attenuated VZV vaccine was developed in 1975 [8]. The vaccine has been licensed in many countries and in 1995 was introduced into the routine immunization schedule for healthy children in the United States [9]. Many other countries are currently studying the possibility of mass vaccination [10-15]. However, some important questions remain which limit the widespread acceptability of the vaccine in these countries. The main concern is that, by reducing the incidence of varicella, vaccination would cause an increase in the average age at infection, which could lead to an overall increase in morbidity [16]. Other concerns are the high number of breakthrough infections in vaccinees and the effect of vaccination on the incidence of zoster $[17,18]$.

To evaluate the overall impact and cost-effectiveness of varicella vaccination, it is necessary to understand the pre-vaccine epidemiology of both primary and reactivated VZV infection. This paper analyses surveillance and hospitalization data from the United Kingdom and Canada to investigate the following key epidemiological characteristics of varicella and zoster in developed countries: (1) age distribution; (2) annual incidence; (3) seasonal patterns; (4) the age-specific force of varicella infection; and (5) rate and duration of hospitalization.

\section{METHODS}

\section{Data}

Canada

Population-based data were obtained using annual physician billing claims and hospital separations from the province of Manitoba during 1979-97. During this interval the population of Manitoba varied from 1.08 to 1.16 million with approximately 16000 births per year. The province is generally representative of Canada in indicators of health status, socio-economic status and provincial expenditures on health care [19, 20]. The methodology for abstracting health claims data in Manitoba has previously been validated and documented [21]. The physician claims files include an encrypted personal health identification number (PHIN), date of service, physician specialty, clinical setting and a single 3-digit International Classification of Disease code (ICD-9) indicating the reason for the claim. For zoster, only the first claim for an individual was included regardless of the time interval between first and second or more claims in order to measure incidence.
The hospital separations file covers both acute and long term stay hospitals, and includes up to 16 five digit ICD-9 codes, the PHIN, the admission and discharge dates, urgency of admission, surgical procedure codes and status at discharge. Complete data are available for all fiscal years from 1979 through to the present, which for this study included fiscal year 1997.

\section{United Kingdom}

For the United Kingdom, information on the agespecific consultation rate for varicella and zoster is available through the Royal College of General Practitioners (RCGP), which instituted a sentinel surveillance programme in 1967 using a representative sample of the practitioners throughout England and Wales [22]. The diagnosis, age and sex of each patient with a new illness are reported weekly. Additional agespecific consultation rates for varicella and zoster are available from the National Survey of Morbidity in General Practice (MSGP4) database, which was derived from a survey of 60 English and Welsh general practices in 1991-2 [23]. The study covered a $1 \%$ sample of the population of England and Wales (502493 patients, 468042 person-years at risk). The database includes the number of persons consulting by age and ICD-9 diagnosis.

Hospitalization data for the UK was extracted from Hospitalization Episode Statistics (HES database) for $1995 / 6$, which covers every inpatient admission in England during this period (approximately 49000000 person-years at risk). Data obtained from the HES database included the dates of admission, discharge and birth, and discharge diagnosis coded by ICD-10.

An identical algorithm was used to identify varicella and zoster hospitalizations for both the Canadian and UK hospital datasets. The specific algorithm relies on the discharge diagnosis based on the ICD-9 and-10 codes for varicella (052 and B01 respectively) and zoster (053 and B02). All claims with either 052, B01, 053 or B02 were included. For both Manitoba and England all hospital separations with a varicella or zoster diagnostic code in one or more of the first three positions were considered to be admissions due to a VZV unless major trauma was listed as the principal diagnostic code (e.g. fracture, burns, etc). Finally, all admissions with a length of stay of 0 days were assumed to represent outpatient procedures or cancelled elective admissions and were thus excluded from analysis. 


\section{Force of infection of varicella}

The force of infection is the instantaneous incidence rate of infection amongst susceptibles. It was estimated, here, from physician consultation data (Manitoba billings, RCGP and MSGP4 data [22, 23]. To estimate the force of infection from physician consultation data, consultation rates were adjusted given that physicians do not see all children with chickenpox. The proportion of children with varicella seen by a physician in Manitoba for the 0-6 age groups was estimated by dividing, for each age, the rate of consultation of the 1990 Manitoba birthcohort by the incidence rate from the Manitoba school survey [24] performed on the same cohort. The estimated percent of children with varicella seen by a physician for each year of age for $0-6$ years were 57 , $48,32,21,22,27$ and $30 \%$. These estimates fit the reported data for frequency of physician visits for children with chickenpox [25-28]. Similar estimates for those over 7 years of age were derived from the literature assuming that all individuals contract varicella during their lifetime [1,29]. The proportion for 7-10, 11-14, 15-24, 25-34, 35-54 and 55+ age groups respectively was $30,37,65,90,95$ and $100 \%$. For physician consultation data, the force of infection was calculated by using Farrington's [30] functional form to generate an expected proportion of individuals of age $\mathrm{X}$ who would have been exposed to the virus. The function is fitted to the observed age-specific proportion of individuals with history of infection using maximum likelihood methods.

\section{Lifetime risk of zoster}

The lifetime risk of at least one reactivation of VZV was estimated by calculating the cumulative incidence of zoster and assuming life expectancy is 78 years (average life expectancy at birth in Manitoba and England during the 1990s (www.statcan.ca and www.doh.gov.uk). The cumulative incidence was calculated from the average age-specific rates of incident zoster consultation in Manitoba and England and Wales between 1990 and 1997.

\section{RESULTS}

\section{Varicella}

Age dependent annual consultation rates

Since 1979 the proportion of all varicella consultations among children under 15 years has remained roughly
Table 1. Average consultation rates (per 100000 population-year) for varicella in Canada and the United Kingdom, 1979-97*

\begin{tabular}{lcrllr}
\hline \hline & \multicolumn{2}{l}{ Varicella } & & \multicolumn{2}{l}{ Herpes zoster } \\
\cline { 2 - 3 } \cline { 5 - 6 } Age group & Canada & UK & & Canada & UK \\
\hline $0-4$ & 2345 & 3414 & & 64 & 76 \\
$5-14$ & 1306 & 1696 & & 121 & 179 \\
$15-44$ & 115 & 249 & & 192 & 210 \\
$45-64$ & 15 & 30 & & 423 & 470 \\
$65+$ & 12 & 14 & & 812 & 771 \\
\hline \hline
\end{tabular}

* Rates are per 100000 population-year. Population estimates were taken from the Office of National Statistics for England and Statistics Canada for Manitoba.

stable at around $85 \%$ for both Canada and the United Kingdom. The average consultation rates for varicella in Canada and the United Kingdom between 1979 and 1997 are presented in Table 1.

There was a remarkable increase in varicella consultation rates in children under 5 in the United Kingdom. In 1979-83 and 1994-8 consultation rates in the UK increased by $135 \%$ to 4467 consultations per 100000 person-year in children under 5 years (Fig. 1b). In addition, consultations in older children (5-14 years) decreased by $53 \%$ to 1052 consultations per 100000 person-year over the same time period. Canadian data show an upward shift in varicella consultation rates for all age groups, with a proportionally higher increase in adults $(175 \%$ increase to 162 consultations per 100000 person-year in 1979-83 and 1993-7, Fig. 1a).

\section{Seasonality}

Varicella cases increase throughout the school year (September to June) for both the United Kingdom and Canada then fall sharply during summer vacation (June to September) (Fig. 2a,d). Interestingly, Canada has one peak (June, Fig. 2a) while the United Kingdom has two peaks of varicella incidence (middle of March and June, Fig. 2d). The seasonal pattern seen in the 0-14 age group becomes less pronounced with increasing age groups (Fig. 2b, c, e, f).

\section{Force of infection}

Estimated values for the force of infection differed between Canada and the United Kingdom among children under 12 years (Table 2). For children under 1, the United Kingdom force of infections was $0 \cdot 11$ 

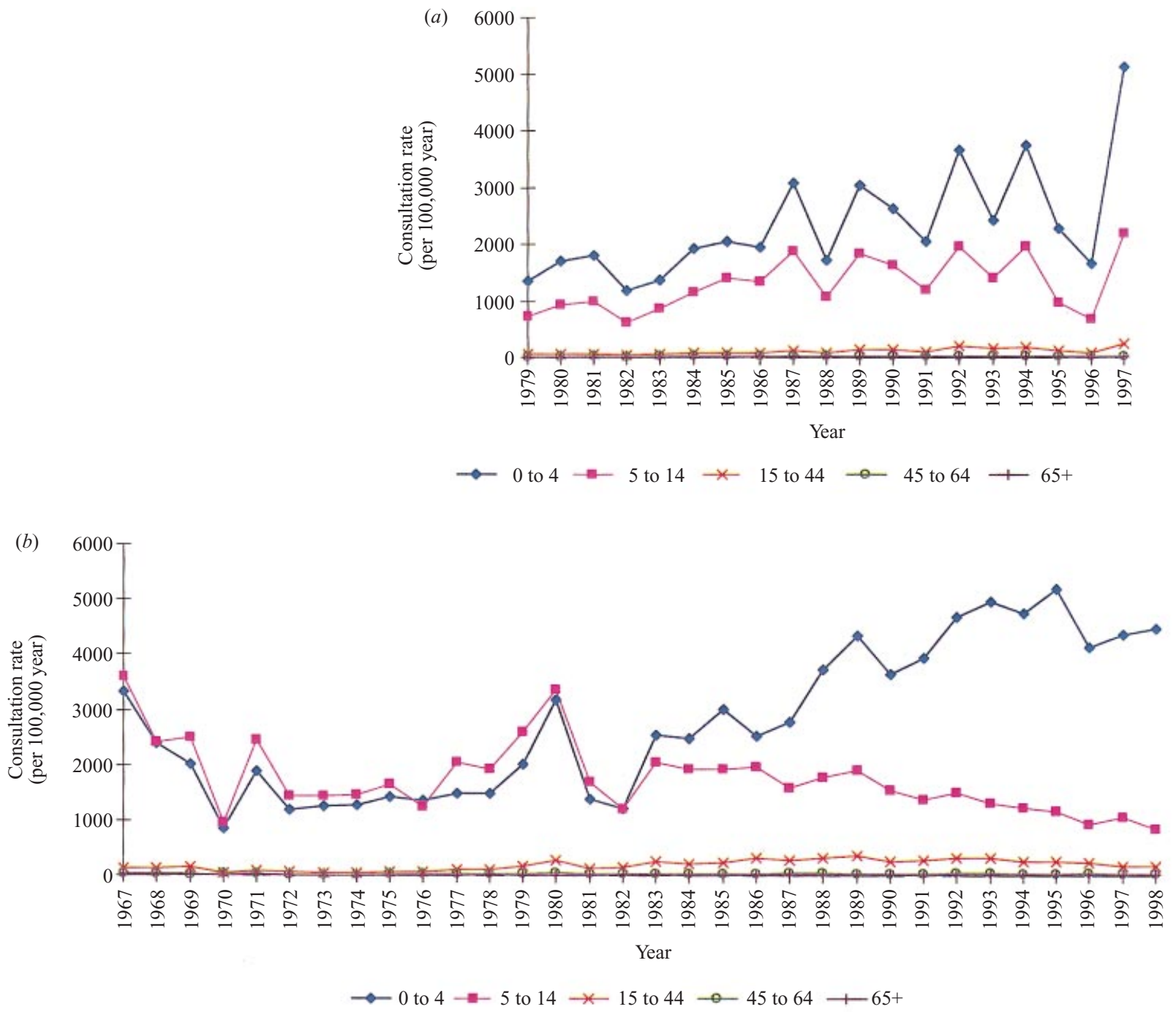

Fig. 1. Annual varicella consultation rate. Annual age-specific varicella consultation rate in (a) Manitoba from 1979-97, and (b) England and Wales from 1967-98. The X-axes in the main panels are aligned.

infections per susceptible-year, compared to 0.05 in Canada. Conversely among children of 5-11 years, there was an estimated $0 \cdot 20$ infections per susceptibleyear, compared to 0.15 in the United Kingdom.

\section{Hospitalization and inpatient days}

Hospitalization per 100000 population and proportion of hospitalizations per case of varicella are strikingly similar between the United Kingdom and Canada (Table 3). The proportion admitted to hospital per varicella case is high in children under 2 years of age ( $\approx 2 \%$ of cases), falls to approximately $0.50 \%$ in $2-18$ year-olds then increases significantly throughout adult life to $6 \%$ in those over 65 years.

The average number of inpatient days per hospitalized case of varicella also increases with age from 4 days in children to 17 days in adults over 65 years. Although the shape of the relationship between average inpatient stay and age is similar between Canada and the United Kingdom, Canada has systematically a higher number of days in hospital (average of 2 days more per hospitalization, Table 3 ).

The number of hospitalizations and average number of inpatient days per hospitalized case of varicella has not significantly changed in Canada since 1979. However, since 1979, the overall number of hospitalizations has increased in the United Kingdom [1] while overall rates of infection have remained relatively stable. The shift of varicella infection in the United Kingdom from the 5-15 age group, which have the lowest severity, to children under 5 and adults both of whom have higher severity (Table 3) may explain the overall increase in hospitalization. 

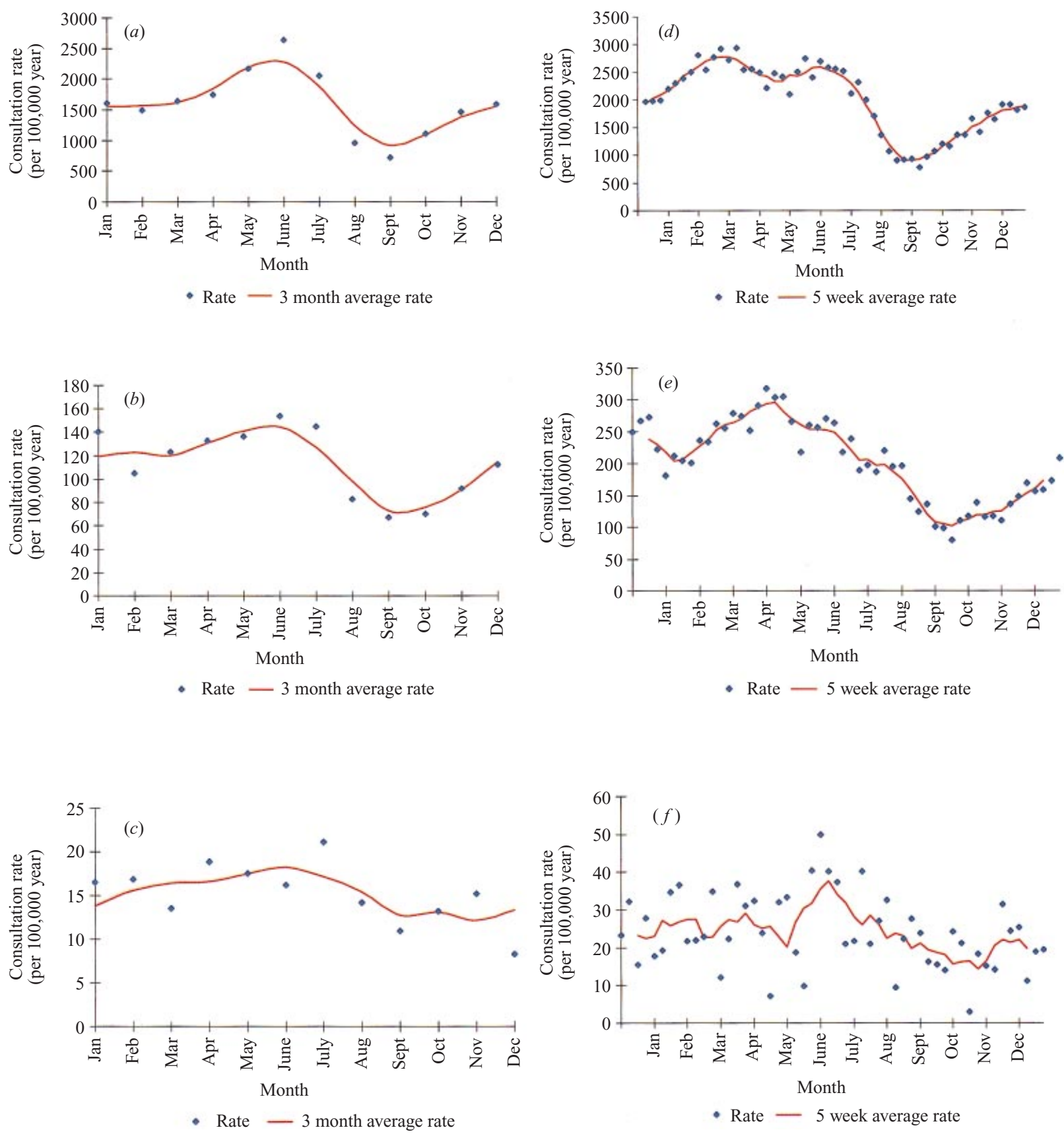

Fig. 2. Varicella seasonality. Average monthly rate of consultations for varicella in Manitoba between 1979 and 1997 for age groups (a) 0-14 years, (b) 15-44 years and (c) over 45 years. Average weekly rates of varicella consultation in England and Wales between 1979 and 1997 for ages. (d) 0-14 years, (e) 15-44 years and (f) over 45 years.

\section{Zoster}

Age dependent annual consultation rates

The estimated average lifetime risk of at least one VZV reactivation in Canada and the United Kingdom between 1990 and 1997 was 28 and 30\% respectively. The age distribution of zoster is similar between Canada and the United Kingdom. The proportion of zoster consultations in each age group has remained relatively constant through time with over $60 \%$ of consultations occurring in individuals older than 45 years of age and less than $9 \%$ in children under 15 years. However, in the United Kingdom, a slight increase of zoster consultations can be observed in individuals over 65 years of age (from $27 \%$ in 1979 to $39 \%$ in 1998). The average consultation rates for zoster in Canada and the United Kingdom between 1979 and 1997 are presented in Table 1. Again, the 
Table 2. Estimated varicella force of infection (infections per susceptible-year) by age group

\begin{tabular}{lll}
\hline \hline Age group & Canada* & $\mathrm{UK} \dagger$ \\
\hline $0-1$ & $0 \cdot 05$ & $0 \cdot 11$ \\
$2-4$ & $0 \cdot 16$ & $0 \cdot 18$ \\
$5-11$ & $0 \cdot 20$ & $0 \cdot 15$ \\
$12-18$ & $0 \cdot 10$ & $0 \cdot 09$ \\
$19-24$ & $0 \cdot 09$ & $0 \cdot 09$ \\
$25-44$ & $0 \cdot 08$ & $0 \cdot 08$ \\
$45-64$ & $0 \cdot 05$ & $0 \cdot 07$ \\
$65+$ & $0 \cdot 04$ & $0 \cdot 07$ \\
\hline \hline
\end{tabular}

* Manitoba medical billings data, 1990-3.

$\dagger$ RCGP and MSGP4 data, 1991-2.

average consultation rates are generally higher in the United Kingdom than in Canada.

Since the beginning of the 1980s, the overall zoster consultation rate has been slowly increasing in Canada and the United Kingdom. Between 1979 and 1997 the overall zoster consultation rate has risen from 258 to 348 and 315 to 382 per 100000 years in Canada and the United Kingdom respectively.

The sharp fall of UK varicella consultation rates in 5-14 year olds since the early 1980s (Fig. 1 b) coincides with an increase in zoster in the same age group (53\% increase to 233 zoster consultations per 100000 person-year between 1983 and 1998). Temporal correlation between varicella and zoster for the 5-14 age group was significant between 1983 and 1998 $(r=-0 \cdot 72)$. No temporal correlation was identified between the other age groups.

\section{Seasonality}

Zoster does not seem to possess a seasonal pattern. The weekly and monthly average age-specific rates of zoster consultation display no identifiable periodicity in the United Kingdom and Canada. Furthermore, zoster does not seem to be correlated to the seasonality of varicella which suggests that if exposure to varicella does boost against zoster then the average period of boosting is long relative to the epidemic time scale (1 year).

\section{Hospitalization and inpatient days}

The age-specific hospitalization rate, proportion of hospitalized zoster cases and average number of inpatient days are very similar between Canada and the United Kingdom (Table 3). The proportion of inpatient hospitalizations per zoster case is approxi- mately $3 \%$ in the $0-4$ year age group, decreases to $1 \%$ in 5-14 year olds, then increases throughout adult life to more than $10 \%$ in individuals over 65 years (Table 3). Furthermore, the average number of inpatient days per zoster admission increases with age from approximately 6 days in $0-4$ year olds to 19 days in the elderly (over 65 years) (Table 3 ).

\section{DISCUSSION}

The overall epidemiology of varicella and zoster (i.e. age distribution, incidence, seasonality and morbidity) is similar between Canada and the United Kingdom and is consistent with studies in other developed countries [1, 6, 31-39]. Though sentinel reporting may overestimate the proportion of cases in older age groups (due to a larger proportion consulting their physicians), most consultations are for childhood infection. The age-specific distribution of varicella cases reported by general practitioners is similar between the United Kingdom and Canada (around $85 \%$ are in children under 15 years) and is comparable to surveillance data in France (92\% of consultations) and Scotland $(79 \%)[1,33]$. The highest consultation rate is in 0-4 year olds for Canada and the United Kingdom. Finally, it should be noted that the overall consultation rates are slightly higher in the United Kingdom than in Canada. This is to be expected since varicella cases reported by general practitioners are determined by patient consultation patterns, which partly depend on the primary health care system of each country.

The shape of the force of infection estimated for Canada and the United Kingdom (increasing in the pre-school years, peaking during primary school and declining thereafter) is consistent with other countries and with that of other childhood infections such as measles, mumps and rubella [40, 41]. This suggests that preschool and school-age mixing is an important determinant of varicella transmission as with other childhood infections such as measles and rubella.

The age-specific consultation rate from Canada and the United Kingdom suggest that varicella has an annual epidemic cycle with more cases occurring during spring. Annual periodicity of varicella has also been observed in France and the United Kingdom [33, 34]. Contrary to Canada, which has one peak (June, Fig. 2a), the United Kingdom has two peaks of varicella incidence (middle of March and June, Fig. $2 \mathrm{~d})$. This difference in seasonality might be due to the school calendar. In the United Kingdom, spring 
Table 3. Age specific risk of varicella and herpes zoster hospitalization and average length of stay in the UK (1995/6) and Canada (1979-97)

\begin{tabular}{|c|c|c|c|c|c|c|}
\hline \multirow[b]{2}{*}{ Age group } & \multicolumn{2}{|c|}{$\begin{array}{l}\text { Hospitalization } \\
\text { (per } 100000 \text { population)* }\end{array}$} & \multicolumn{2}{|c|}{$\begin{array}{l}\text { Hospitalization } \\
(\text { per case, } \%) \dagger\end{array}$} & \multicolumn{2}{|c|}{$\begin{array}{l}\text { Average length of } \\
\text { stay (days) }\end{array}$} \\
\hline & UK & Canada & UK & Canada & UK & Canada \\
\hline \multicolumn{7}{|l|}{ Varicella } \\
\hline $0-1$ & 74 & 71 & 1.6 & $1 \cdot 8$ & $2 \cdot 6$ & $5 \cdot 5$ \\
\hline $2-4$ & 36 & 40 & $0 \cdot 8$ & $0 \cdot 4$ & $2 \cdot 9$ & $5 \cdot 0$ \\
\hline $5-11$ & 8 & 11 & $0 \cdot 3$ & $0 \cdot 2$ & $3 \cdot 4$ & $4 \cdot 5$ \\
\hline $12-18$ & 2 & 2 & $0 \cdot 1$ & $0 \cdot 4$ & $8 \cdot 4$ & $4 \cdot 6$ \\
\hline $19-24$ & 4 & 2 & $1 \cdot 2$ & $0 \cdot 5$ & $3 \cdot 2$ & $4 \cdot 3$ \\
\hline $25-44$ & 4 & 3 & $1 \cdot 3$ & $1 \cdot 4$ & 4.9 & $8 \cdot 7$ \\
\hline $45-64$ & 1 & 1 & 1.9 & 1.9 & $8 \cdot 0$ & $10 \cdot 2$ \\
\hline $65+$ & 1 & 2 & $5 \cdot 5$ & $7 \cdot 0$ & $16 \cdot 1$ & $18 \cdot 0$ \\
\hline \multicolumn{7}{|c|}{ Herpes zoster } \\
\hline $0-4$ & 2 & 1 & $4 \cdot 4$ & $2 \cdot 2$ & $6 \cdot 2$ & $5 \cdot 1$ \\
\hline $5-14$ & 2 & 2 & $0 \cdot 6$ & $1 \cdot 4$ & $4 \cdot 9$ & $4 \cdot 6$ \\
\hline $15-44$ & 3 & 2 & $1 \cdot 1$ & $1 \cdot 0$ & $7 \cdot 2$ & $8 \cdot 0$ \\
\hline $45-64$ & 13 & 12 & $2 \cdot 4$ & $2 \cdot 8$ & $10 \cdot 4$ & $11 \cdot 6$ \\
\hline $65+$ & 148 & 86 & $14 \cdot 4$ & $10 \cdot 6$ & $18 \cdot 9$ & $20 \cdot 0$ \\
\hline
\end{tabular}

* Population estimates were taken from the Office of National Statistics for England and Statistics Canada for Manitoba. $\dagger$ The proportion of cases hospitalized relates to the number of hospitalizations divided by the estimated number of cases for the same time period. Cases of varicella were calculated by adjusting the observed number of consultations by the estimated age specific percent of children with varicella seen by a physician (see methods for values). Zoster consultation rates were assumed to be reasonable estimates of incidence rates.

vacation lasts at least 2 weeks (twice the duration of the varicella infectious period) but in Canada it only lasts a week. Annual periodicity declines with age but is still apparent in adults less than 45 years of age. This might indicate a higher degree of mixing between children under 15 and younger adults (children with parents) than with adults over 45 (children with grandparents). On the other hand the lack of seasonality in adults over 45 could be due to a smaller number of cases (i.e. lack of power to detect seasonality) and/or be due to a misclassification of some zoster cases as varicella.

Because of its high severity [1, 37, 38] most individuals with zoster are likely to consult a general practitioner. Zoster consultation rates are thus likely to be a reasonable estimate of incidence rates. Similar to other industrialized countries [37, 39], more than $60 \%$ of zoster cases in Canada and the United Kingdom are in adults over 45 years old. The highest rate of zoster is in $65+$ year olds $[34,38]$ and seems to be increasing in the elderly population. This is at least partly attributable to the ageing of the population. Since the rates of reactivation increase with age especially for those aged 75 and older, an upward shift in the age distribution of the elderly can increase zoster rates in over 65 year age group. Indeed, when Canadian zoster rates are stratified into $65-74$ and $75+$ year age groups the specific rates increase less over time than the rate for the un-stratified $65+$ age group.

Differences in the epidemiology of varicella and zoster between Canada and the United Kingdom can provide us with a better understanding of the dynamics of the varicella zoster virus. Differences in seasonality between the United Kingdom and Canada illustrate that contact patterns between school terms and vacation play an important role in the dynamics of varicella. Furthermore, an important shift in the age-specific incidence of infection has been observed in the United Kingdom. Interestingly, the shift in the age distribution of consultations in the United Kingdom coincides with a significant increase in children attending preschool [1, 42, 43]. Between 1970 and 1992 the number of children attending preschool has increased from 10 to $50 \%$ [1]. In contrast, the proportion of children attending preschool remained relatively constant in Canada at 10\% between 1979 and 1994 (www.stat.gouv.qc.ca). The dramatic change in preschool attendance in the United Kingdom, by increasing the opportunity for effective contact be- 
tween children under 5, might be responsible for such a shift in the age distribution of varicella [1]. Similar trends have been observed in the United States [31, 44, 45]. Changes in the consultation patterns of children and in the age distribution of the population might also contribute to the shift in the age distribution of reported varicella cases. It is interesting to note that, the fall of UK varicella consultation rates in 5-14 year olds coincides with an increase in zoster in the same age group. This reduction could be because more cases of varicella in $0-4$ year olds increases the potential for reactivation during childhood (i.e. 5-14 years), and perhaps a fall in natural boosting of immunity due to a decline in the incidence of varicella [6]. The shift in the age at infection in the United Kingdom and difference in seasonality between the United Kingdom and Canada indicate that school and pre-school contact patterns must be carefully taken into account when assessing the impact of vaccination.

Hospitalization and inpatient days should reflect the age-specific severity (morbidity) of disease. Hospital admission data from Manitoba and England show a steep increase in both varicella and zoster hospitalizations and average number of inpatient days with age. This is consistent with results from the United States although the age-specific proportion of cases that result in hospitalization is slightly lower in the United States [32, 34-36, 46]. Theses dissimilarities are most likely due to the difference in the structure of the various health systems. Since, currently, varicella occurs mainly in children the increase in severity with age does not lead to a high number of varicella related hospital days. However, mass immunization results in an increase in the average age at infection in those who are not immunized. Therefore, there is a danger that mass immunization can lead to an increase in hospitalization and inpatient days. Such perverse outcomes from mass infant vaccination has been observed for rubella in Greece [47]. However, modelling work using the Manitoba age-specific hospitalization and inpatient day data suggests that, regardless of vaccine coverage, infant vaccination is unlikely to shift the average age at infection to such an extent that the total morbidity will be worse than the pre-vaccination state [16]. Although immunization is unlikely to cause more harm than good, any increase in the number of adult cases would deleteriously affect the cost-effectiveness of varicella vaccination.

Zoster is considered to be much more severe than varicella. Contrary to general belief, age-specific severity, as measured by the age-specific proportion of hospitalization per case and inpatient days, is only slightly higher for zoster than varicella (Table 3). However, the overall burden of disease is considerably higher for zoster because over $80 \%$ of cases occur in adults (less than $15 \%$ for varicella). The total number of inpatient days attributable to zoster in England for 1995/6 was 61937 days compared to 10992 days for varicella. In Manitoba the average number of inpatient days per year between 1979 and 1997 was 2815 days for zoster compared to 425 days for varicella. This corresponds to a 6- to 7-fold difference between the number of annual zoster and varicella inpatient days. Furthermore, since the validity of diagnostic codes for varicella appears to decrease markedly after age 50 years [35] the relative contribution of varicella to VZV hospitalizations might be overestimated among older individuals.

Zoster may occur more frequently in adults who have not been boosted by varicella contacts (6). A reduction of varicella incidence after mass immunization could lead to an increase in the incidence of zoster. This could have a major impact on the overall effectiveness and cost-effectiveness of varicella vaccination [16]. Furthermore, the VZV vaccine is the first of its kind that actually induces latency (reactivations may be due to the vaccine). Surveillance of zoster incidence should be a priority in countries where varicella immunization is underway. The Manitoba and England and Wales surveillance systems would allow a detailed surveillance of both zoster and varicella should mass immunization take place.

\section{ACKNOWLEDGEMENTS}

This work was supported by the UK Medical Research Council (grant number G9818303) and the Laboratory Center for Disease Control in Canada (LCDC) and by the Winnipeg Children's Hospital Foundation. We would like to thank Dr Douglas Fleming of the Royal College of General Practitioners, and the Health Information Services, Manitoba Health, for the provision of data.

\section{REFERENCES}

1. Fairley CK, Miller E. Varicella-zoster virus epidemiology - a changing scene? J Infect Dis 1996; 174 (Suppl 3): S314-9. 
2. Guess HA, Broughton DD, Melton LJ, Kurland LT Population-based studies of varicella complications. Pediatrics 1986; 78 (Suppl): 723-7.

3. Haake DA, Zakowski PC, Haake DL, Bryson YJ. Early treatment with acyclovir for varicella pneumonia in otherwise healthy adults: retrospective controlled study and review. Rev Infect Dis 1990; 12: 788-98.

4. Preblud SR. Age-specific risks of varicella complications. Pediatrics 1981; 68: 14-7.

5. Gershon AA, Takahashi M, White CJ. Varicella vaccine. In Vaccines, 3rd edn. Plotkin SA, Orenstein WA, eds. W. B. Saunders Co. 1999: 475-507.

6. Hope-Simpson RE. The nature of herpes zoster: a longterm study and a new hypothesis. Proc R Soc Med 1965; 58: 9-12.

7. Miller E, Marshall R, Vurdien J. Epidemiology, outcome and control of varicella-zoster infection. Rev Med Microbiol 1993; 4: 222-30.

8. Takahashi M, Okuno $\mathrm{Y}$, Otsuka $\mathrm{T}$, Osame $\mathrm{J}$, Takamizawa A. Development of a live attenuated varicella vaccine. Biken J 1975; 18: 25-33.

9. Committee on Infectious Diseases. Live attenuated varicella vaccine. Pediatrics $1995 ;$ 95: 791-6.

10. Scuffham PA, Lowin AV, Burgess MA. The costeffectiveness of varicella vaccine programs for Australia. Vaccine 1999; 18: 407-15.

11. Beutels P, Clara R, Tormans G, Van Boorslaer E, Van Damme P. Costs and benefits of routine varicella vaccination in Geman children. Infect Dis 1996; 174 (Suppl 3): S335-41.

12. Scuffham P, Devlin N, Eberhart-Phillips J, Wilson-Salt R. The cost-effectiveness of introducing a varicella vaccine to the New Zealand immunisation schedule. Soc Sci Med 1999; 49: 763-79.

13. Domingo JD, Ridao M, Latour J, Ballester A, Morant A. A cost benefit analysis of routine varicella vaccination in Spain. Vaccine 1999; 17: 1306-11.

14. Coudeville L, Paree F, Lebrun T, Sailly JC. The value of varicella vaccination in healthy children: cost-benefit analysis of the situation in France. Vaccine 1999; 17: $142-51$

15. Health Canada Proceedings of the National Varicella Consensus Conference, Canada CDR 1999; 25 (Suppl): $1-29$.

16. Brisson M, Edmunds WJ, Gay NJ, Law B, De Serres G. Modelling the impact of immunization on the epidemiology of varicella zoster virus. Epidemiol Infect 2000; 125: 651-69.

17. Brisson M, Edmunds WJ, Gay NJ, Law B, De Serres G. Analysis of varicella vaccine breakthrough rates: Implications for the effectiveness of immunisation programs. Vaccine $2000 ; \mathbf{1 8}$ : 2775-8.

18. Garnett GP, Grenfell BT. The epidemiology of varicella-zoster virus infections: the influence of varicella on the prevalence of herpes-zoster. Epidemiol Infect 1992; 108: 513-28.

19. Shanahan M, Gousseau C. Using the POPULIS framework for interprovincial comparisons of expenditures on health care. Medical Care 1999; 37 (Suppl) : S83-100.
20. Law B, MacDonald N, Halperin S, et al. The Immunization Monitoring Program Active (IMPACT) prospective five year study of Canadian children hospitalized for chickenpox or an associated complication. Pediatr Infect Dis J 2000; 19: 1053-9.

21. Roos LL, Mustard CA, Nicol JP, McLerran DF, Malenka DJ, Young TK, Cohen MM. Registries and administrative data: organization and accuracy. Medical Care $1993 ; 31: 201-12$.

22. Fleming DM. Weekly returns service of the Royal College of General Practitioners. Comm Dis Publ Hlth 1999; 2: 96-100.

23. McCormick A, Fleming D, Charlton J. Morbidity statistics from general practice: Fourth National Study 1991-1992. Office of Population Censuses and Survey. Series MB5:3. London: HMSO, 1995: 1-365.

24. Law BJ, Brownell MD, Walld R, Roos LL. Chickenpox in Manitoba: A population-based assessment using the Manitoba Health Services Commission Database. Poster presentation at the Canadian National immunization Conference, Partnerships for Health through Immunization. 6-9, Dec 1998, Calgary, Alberta.

25. Lieu TA, Cochi SL, Black SB, et al. Cost-effectiveness of a routine varicella vaccination program for US children. JAMA 1994; 271: 375-81.

26. Sulivan-Bolyai JZ, Yin EK, Cox P, et al. Impact of chickenpox on households of healthy children. Pediatr Infect Dis J 1987; 6: 33-5.

27. Saddier P, Floret D, Guess HA, et al. Cost of varicella in France: a study in day care centers. J Infect Dis 1998; 178: S58-S63.

28. Law B, Fitzsimon C, Ford-Jones L, et al. Cost of chickenpox in Canada: Part I. Cost of uncomplicated cases. Pediatrics 1999; 104: 1-6.

29. Ratnam S. Varicella susceptibility in a Canadian Population. Can J Infect Dis 2000; 11: 249-53.

30. Farrington CP. Modeling forces of infection for measles, mumps and rubella. Stat Med 1990; 9: 953-67.

31. Finger R, Hughes JP, Meade BJ, et al. Age-specific incidence of chickenpox. Publ Hlth Rep 1994; 109: $750-5$.

32. Wharton M, Fehrs LJ, Cochi SL, et al. Health impact of varicella in the 1980s (abstract). In: Program and abstracts of the 30th Interscience Conference on Amtimicromial Agents and Chemotherapy, Atlanta, Georgia, 21-24 Octob 1990.

33. Deguen S, Chau NP, Flahaut A. Epidemiology of Chickenpox in France (1991-1995). J Epidemiol Comm Hlth 1998; 52 (Suppl 1): 46S-49S.

34. Wharton $\mathrm{M}$. The epidemiology of varicella-zoster virus infections. Infect Dis Clin North America 1996; 10: 571-81.

35. Choo PW, Donahue JG, Manson JE, Platt R. The epidemiology of varicella and its complications. J Infect Dis 1995; 172: 706-12.

36. Guess HA, Broughton DD, Melton LJ, Kurland LT. Chickenpox hospitalisations among residents of Olmsted Country, Minnesota 1962 through 1981. Am J Dis Child 1984; 138: 1055-7.

37. Paparatti UL, Arpinelli F, Visona G. Herpes zoster and 
its complications in Italy: an observational survey. J Infect 1999; 38: 116-20.

38. Ragozzino MW, Melton LJ, Kurland LT, Chu CP, Perry HO. Population-based study of herpes zoster and its sequelae. Medicine 1982; 61: 310-6.

39. de Moragas JM, Kierland RR. The outcome of patients with herpes zoster. AMA Arch Derm 1975; 7: 193-6.

40. Halloran ME, Cochi SL, Lieu TA, Wharton M, Fehrs L. Theoretical epidemiologic and morbidity effects of routine varicella immunization of preschool children in the United States. Am J Epidemiol 1994; 140: 81-104.

41. Edmunds WJ, Gay NJ, Kretzschmar M, Pebody RG, Wachmann H. The pre-vaccination epidemiology of measles, mumps and rubella in Europe: implications from modelling studies. Epidem Infect 2001; 125: 635-50.

42. Department of Education and Science. Statistical bulletin, 1982-91. London: Government Statistical service, 1992.
43. Fleming DM, Norbury CA, Crombie DL. Annual and seasonal variation in the incidence of common diseases. Twenty-three years' experience of the weekly returns service of the Royal College of General Practitioners. Occasional paper 53. London: Royal College of General Practitioners, 1991.

44. Jones SE, Armstrong CB, Bland C, Walter EB, Clements DA. Varicella prevalence in day-care centers. Pediatr Infect Dis J 1995; 14: 404-5.

45. Yawn BP, Yawn RA, Lydick E. Community impact of childhood varicella infections. J Pediatr 1997; 130: 759-65.

46. Lin F, Hadler JL. Epidemiology of primary varicella and herpes zoster hospitalizations: the pre-varicella vaccine era. J Infect Dis. 2000; 181: 1897-905.

47. Panagiotopoulos T, Antoniadou I, Valassi-Adam E. Increase in congenital rubella occurrence after immunisation in Greece: retrospective survey and systematic review. BMJ 1999; 319: 1462-7. 